tổn thương dây thần kinh chi dưới để lại hậu quả nặng nề, tỷ lệ tổn thương hoàn toàn chiếm $64,5 \%$, tổn thương không hoàn toàn chỉ chiếm $35,5 \%$. Vận tốc dẫn truyền, biên độ của các dây thần kinh bên tổn thương có chỉ số giảm đáng kể so bên lành. Trong khi đó thời gian tiềm của các dây thần kinh bên tổn thương không có sự thay đổi lớn so với bên lành, các kết quả trên tương đồng với kết quả của nghiên cứu trước đây của Paige C. Roy và cộng sự [4].

Hoạt động điện tự phát gặp ở hầu hết các bệnh nhân $(95,2 \%)$ và có $61,3 \%$ các trường hợp là có hiện tượng kết tập và giao thoa. Tuy nhiên chỉ gặp 7\% có hình ảnh đơn vị vận động tại trạng thái co cơ.

\section{KẾT LUÂN}

Triêu chứng lâm sàng và điên sinh lý thần kinh cơ trong tổn thương dây thần kinh hông to và các nhánh do tổn thương là rất đa dạng: bên tổn thương thường gặp là bên trái $(72,6 \%)$, vị trí hay gặp nhất là khớp gối $(45,2 \%)$, thần kinh mác chung là dây thần kinh dễ bị tổn thương nhất ( $54,8 \%)$, tổn thương hoàn toán chiếm đa số $(64,5 \%)$... phụ thuộc vào vị trí, thời gian và hình thái tổn thương.

\section{TÀI LIÊU THAM KHẢO}

1. Babaei-Ghazani A., Eftekharsadat B., Samadirad B. và công sự. (2017). Traumatic lower extremity and lumbosacral peripheral nerve injuries in adults: Electrodiagnostic studies and patients symptoms. J Forensic Leg Med, 52, 89-92.

2. Immerman $I$. và Grossman J.A.I. Lower Extremity Nerve Trauma. Bull Hosp Joint Dis, 10.

3. Gosk J., Rutowski R., và Rabczyñski J. The lower extremity nerve injuries - own experience in surgical treatment. Folia Neuropathol, 5.

4. Roy P.C. (2011). Electrodiagnostic Evaluation of Lower Extremity Neurogenic Problems. Foot Ankle Clin, 16(2), 225-242.

\title{
ĐÁNH GIÁ KẾT QUẢ LIỆU PHÁP TIÊM COLLAGEN MD-SHOULDER DƯớI HƯớNG DẪN SIÊU ÂM TRONG ĐIỀU TRI VIÊM GÂN TRÊN GAI
}

\section{TÓM TẮT}

Mục tiêu: Đánh giá kết quả điều trị viêm gân trên gai bẳng liệu pháp tiêm Collagen MD-Guna dưới hướng dân siêu âm và đánh giá tác dụng không mong muốn trong 12 tuần theo dõi. Đối tượng và phương pháp nghiên cứu: Nghiên cứu can thiệp lâm sàng, có so sánh với nhóm chứng và so sánh nội nhóm, theo dõi doc trong 12 tuần điều trị trên 61 bênh nhân được chẩn đoán viêm gân trên gai khớp vai và chia thành 2 nhóm. Nhóm 1: gồm 30 bệnh nhân được tiêm Collagen MD-Shoulder $2 \mathrm{ml}$ (1 ống)/lần/tuần vào túi thanh dịch dưới mỏm cùng vai dưới hướng dẫn của siêu âmtrong 5 tuần liên tiếp. Nhóm 2: gồm 31 bệnh nhân được tiêm Depo-Medrol 1 lần duy nhất vào túi thanh dịch dưới mỏm cùng vaidưới hướng dẫn siêu âm. Kết quả: Sau 12 tuần từ thời điểm bắt đâu điều trị: điểm đau VAS trung bình giảm từ 6,8 xuống2,5 điểm (tỷ lệ giảm so với thời điểm trước điều trị là 63,9\%). Điểm đánh giá chức năng vận động khớp vai OSS tăng từ 23,5 $\pm 4,9$ lên 39,7 $\pm 6,9$ điểm (tỷ lệ tăng so với thời điểm trước tiêm là $39,4 \%$ ), cao hơn so với nhóm chứng có ý nghĩa thống kê với $p<0,05$; góc vận động khớp vai tăng từ 122,0 111,3 lên 154,0 $\pm 15,5$ độ (tỷ lệ tăng so với thời điểm trước tiêm là

\section{${ }^{1}$ Bệnh viện $E$ \\ ${ }^{2}$ Trường Đại hoc Y Hà Nội}

Chịu trách nhiệm chính: Nguyễn Vĩnh Ngọc

Email: drngocbm@gmail.com

Ngày nhận bài: 21.6.2021

Ngày phản biên khoa hoc: 16.8.2021

Ngày duyệt bài: 25.8.2021

\section{Đặng Chí Hiếu ${ }^{1}$, Nguyễn Vĩnh Ngọc ${ }^{2}$}

20,6\%). Tỷ lệ đau tăng sau tiêm là 13,3\%. Kết luân: Liệu pháp tiêm Collagen MD-Shoulder dưới hướng dẫn siểu âm trong điều trị viêm gân trên gai có tác dụng giảm đau, cải thiện chức năng vận động và góc vận động sau 12 tuần. Liễu pháp tiêm Collagen MDShoulder dưới hướng dấn siêu âm có hiệu quả giảm đau tương tự, nhưng cải thiện chức năng vận động khớp vai tốt hơn so với liệu pháp tiêm Depo-Medrol ngay từ tuần thứ 5 , kéo dải đến sau 12 tuần điều trị $(\mathrm{p}<0,05)$

Tư khóa: Collagen MD-Shoulder, viêm gân trên gai, tiêm túi thanh dịch dưới mỏm cùng vai dưới hướng dẫn siêu âm. Depo- Medrol.

\section{SUMMARY}

EVALUATE THE RESULTSOF MD-COLLAGEN INJECTION THERAPY UNDER ULTRASOUND GUIDANCEIN THE TREATMENT OF SUPRASPINATUS TENDONITIS

Aims: Evaluate the results of MD-collagen injection therapy in the treatment of supraspinatus tendonitis under ultrasound guidance and evaluate adverse effects of this therapy after 12 weeks of follow-up. Methods: Controlled clinical trial were followed up to 12 weeks in 61 patients with supraspinatus tendonitis, divided into two groups: 30 patients received 5 times in 5 consecutive weeks'sultrasound-guided injection of Collagen MDShoulderinto the subacromial bursa, 31 patientswere given a single ultrasound-guided injection of DepoMedrolinto the subacromial bursa. Results: After 12 weeks of treatment, there was an improvement in VAS, OSS scores, shoulder range of motion in the 
research group: The average VAS were decreased from 6.8 to 2.5 points (reduction rate compared to T0 is $63.9 \%$.), OSS scores were increased from $23,5 \pm$ 4,9 to $39,7 \pm 6,9$ points (the rate of increase compared to T0 is $39.4 \%$ )higher than the placebo group $(p<0,05)$, shoulder range of motion increased from 147,83 to 171,30 (the rate of increase compared to T0 is $20,6 \%$ ). Side effects of the research group was $13.3 \%$ of the patients increased pain at the injection. Conclusion: MD-Shoulder collagen injection therapy under ultrasound guidance in the treatment of supraspinatus tendonitis has the effect of reducing pain, improving motor function and angle of motion after 12 weeks of treatment. Ultrasound-guided MDShoulder Collagen Injection therapy had similar analgesic effect, but improved shoulder mobility better than Depo-Medrol injection therapy from 5 weeks, lasting up to 12 weeks of treatment ( $<<0.05)$.

Keywords: Collagen MD-Shoulder, supraspinatus tendonitis, ultrasound-guided injection into the subacromial bursa, Depo-Medrol.

\section{I. ĐẶT VẤN ĐỀ}

Viêm gân cơ trên gai là tình trạng gân cơ trên gai bị tổn thương và viêm gây đau nhức vùng vai, cánh tay làm giảm chất lượng cuộc sống và đời sống sinh hoạt của người bệnh ${ }^{8}$. Đây là thể bệnh rất thường gặp trong nhóm bênh lý viêm quanh khớp vai (VQKV) thể đơn thuần ${ }^{1,2}$ và thường gặp hơn ở những bệnh nhân trên 50 tuổi. Có nhiều phương pháp được áp dụng để điều trị viêm gân trên gai trong đó phương pháp tiêm corticoid tại chỗ có hiệu quả giảm đau nhanh dưới 6 tuần ${ }^{3}$ và hiện vẫn đang được sử dụng rộng rãi trong thực hành lâm sàng. Tưy nhiên, phương pháp này lại có thể làm tăng nguy cơ đứt gân sau tiêm ${ }^{4}$, cũng như chỉ có tác dụng ngắn hạn.

Hiện nay liệu pháp tiêm Collagen MDShoulder để điều trị tại chố cho các thể bệnh trong nhóm bệnh lý VQKKV đơn thuân là phướng pháp điều trị mới dựa trên nguyên lý bảo tồn và tái tạo giúp hồi phục gân trên gai bị viêm một cách sinh lý nhất theo cấu trúc sinh học. MD Shoulder chứa chủ yếu Collagen type I là một thành phần cơ bản (chiếm $90 \%$ ) trong cấu trúc các gân và các tổ chức phần mềm quanh khớp ${ }^{5}$. Trên thế giới đã có một số nghiên cứu đánh giá hiệu quả của liệu pháp tiêm Collagen tại chỗ trong điều trị VQKV cũng như viêm gân trên gai và cho kết quả tốt, đồng thời ít tác dụng không mong muốn ${ }^{6}$. Tuy nhiên, ở Việt Nam hiện chưa có nghiên cứu nào về điều trị viêm gân trên gai bằng liệu pháp tiêm Collagen MD-Shoulder tại chỗ. Vì vậy, chúng tôi tiến hành đề tài này nhằm đánh giá kết quả điều trị viêm gân trên gai bằng liệu pháp tiêm Collagen MD-Shoulder tại chổ dưới hướng dẫn siêu âm. Với mục tiêu:

1. Đánh giá kêt quả điều trị viêm gan trên gai bằng tiêm Guna Collagen dưới hướng dẫn siêu âm.

2. Nhânn xét tính an toàn của phương pháp điều trị viêm gan trên gai bằng tiêm Guna Collagen dưới hướng dẫn siêu âm.

\section{II. ĐỐI TƯợNG VÀ PHƯƠNG PHÁP NGHIÊN CỨU}

Thiết kế nghiên cứu: Nghiên cứu tiến cứu, can thiệp lâm sàng, theo dõi dọc, có so sánh với nhóm chứng và so sánh nội nhóm.

\section{Đối tượng nghiên cứu:}

Tiêu chuẩn lựa chọn: Đối tượng nghiên cứu (ĐTNC) gồm 61 bệnh nhân (BN) được chẩn đoán viêm gân trên gai: Đau tại mặt trước của khớp vai lan xuống cánh tay, có hoăc không có hạn chế các động tác vận động chủ động của khớp vai, có dâu hiệu cung đau và dấu hiệu Jobe test $(+)$; VAS $\geq 4$. Siêu âm: Gân trên gai tăng kích thước, giảm âm, ranh giới có thể không rõ. Nghiên cứu đã được thông qua Hội đồng Đạo đức Bệnh viện $E$, thời gian tiến hành từ tháng 12/2020 đến tháng 08/2021 và các đối tượng nghiên cứu đồng ý tham gia nghiên cứu.

Tiêu chuẩn loại trừ: những bệnh nhân có tổn thương đứt bàn phần hoặc đứt hoàn toàn gân cơ trên gai. Bệnh nhân đã được điều trị bằng vật lí trị liệu hoặc tiêm Corticosteroid tại chỗ trong vòng 6 tuần. Các bệnh nhân dùng NSAIDs thì phải dừng thuốc trong vòng 1 tuần trước khi tham gia nghiên cứu.

Cỡ mẫu nghiên cứu: Áp dụng phương pháp chọn mẫu thuận tiện.

Nghiên cứu được chia thành 2 nhóm: Nhóm can thiệp có 30BN áp dụng liệu pháp tiêm $2 \mathrm{ml}$ Collagen MD-Shoulder của hãng GUNA dưới hướng dẫn siêu âm vào túi thanh dịch dưới mỏm cùng vai 5 mũi tiêm trong 5 tuần liên tiếp theo phương pháp của $H$, Guerini. Nhóm chứng gồm $31 \mathrm{BN}$ được tiêm 0,5ml Depo-Medrol vào túi thanh dịch dưới mỏm cùng vai dưới hướng dẫn siêu âm một lần duy nhất. Cả hai nhóm đều có thể sử dụng thuốc giảm đau paracetamol $2 \mathrm{~g} / 24 \mathrm{~h}$ trong vòng 5 ngày khi đau nhiêu. Thủ thuật được thực hiện bởi bác sĩ chuyên khoa Cơ xương khớp. Sử dụng máy siêu âm Samsung, đâu dò Linear tần số 5-13Mhz tại khoa Cơ xương khớp Bệnh viện $\mathrm{E}$. Đánh giá kết quả điều trị bệnh nhân dựa trên thang điểm đau VAS (với các mức đánh giá không đau, đau nhẹ, đau vừa, đau nặng), thang điểm đánh giá chức năng vận động khớp vai OSS, góc vận động khớp vai tại các thời điểm trước điêu trị (T0), sau khi bắt đẩu điều trị 1 tuần (T1), tuần thứ 5 sau khi bắt đầu điều trị (T5) (thời điểm sau khi kết thúc điều trị 1 tuần), tuần thứ 8 sau khi bắt đầu điều trị (T8) và tuần 
thứ 12 sau khi bắt đầu điều trị (T12).

Tác dụng không mong muốn của liệu pháp

III. KẾT QUẢ NGHIÊN CỨU

Bảng 1. Đặc điểm chung của các đôi tượng nghiên cứu

\begin{tabular}{|c|c|c|c|c|}
\hline \multicolumn{2}{|c|}{ Đắc điếm } & Nhóm can thiệp & Nhóm chứng & p \\
\hline \multirow{2}{*}{ Tuối (năm) } & $61,9 \pm 10,3$ & $63,9 \pm 10,1$ & $>0,05$ \\
\cline { 2 - 5 } Giới & Nam (n; \%) & $7(\%)$ & 8 & $>0,05$ \\
\cline { 2 - 5 } & Nữ' (n; \%) & 23 & 23 & $>0,05$ \\
\hline \multirow{2}{*}{ BMI (kg/h) } & $23,1 \pm 2,5$ & $22,6 \pm 2,1$ & $>0,05$ \\
\hline VAS (điếm) & $5,65 \pm 0,98$ & $6,00 \pm 1,23$ & $>0,05$ \\
\hline \multicolumn{2}{|c|}{ OSS (điếm) } & $53,92 \pm 8,57$ & $55,28 \pm 10,98$ & $>0,05$ \\
\hline \multicolumn{2}{|c|}{ Góc vận động (độ) } & $122.0 \pm 11.3$ & $149,80 \pm 23,38$ & $>0,05$ \\
\hline
\end{tabular}

Nhận xét: Không có sự khác biệt về tuối, giới, BMI, điếm đau VAS và chức năng vận động khớp vai giữa 2 nhóm nghiên cứu.

Bảng 2: Mức giảm điểm VAS tại các thời điểm nghiên cứu so với thời điểm trước điều $\operatorname{tri}(T 0)(N=61)$

\begin{tabular}{|c|c|c|c|c|}
\hline \multicolumn{2}{|c|}{ Mức giảm độ giảm điểm VAS } & $\begin{array}{l}\text { Nhóm can thiệp } \\
(n=30)\end{array}$ & $\begin{array}{c}\text { Nhóm chứng } \\
(n=61)\end{array}$ & \multirow{3}{*}{$\begin{array}{c}\text { p3 } \\
<0.05\end{array}$} \\
\hline T1-T0 & Mức giảm (TB $\pm Đ L C)$ & $0,8 \pm 0,7$ & $3,7 \pm 1,0$ & \\
\hline \multirow{3}{*}{$\begin{array}{c}\text { T5 - } \\
\text { T0 } \\
\end{array}$} & Tỷ lệ giảm (\%) & $10,9 \pm 10,3$ & $52,6 \pm 14,0$ & \\
\hline & Mức giảm (TB土ĐLC) & $3,3 \pm 0,8$ & $4,5 \pm 1,6$ & \multirow{2}{*}{$<0.05$} \\
\hline & Tỷ lệ giảm (\%) & $49,6 \pm 11,1$ & $63,7 \pm 22,2$ & \\
\hline \multirow{2}{*}{$\begin{array}{c}\text { T8- } \\
\text { T0 }\end{array}$} & Mức giảm (TB土ĐLC) & $3,9 \pm 1,3$ & $4,6 \pm 1,9$ & \multirow{2}{*}{$>0.05$} \\
\hline & Tỷ lệ giảm (\%) & $57,7 \pm 21,0$ & $66,1 \pm 26,8$ & \\
\hline $\begin{array}{c}\text { T12 - } \\
\text { T0 }\end{array}$ & $\begin{array}{c}\text { Mức giảm (TB } \pm \emptyset L C) \\
\text { Tỷ lệ giảm }(\%)\end{array}$ & $\begin{array}{c}4,3 \pm 2,0 \\
63,9 \pm 31,1\end{array}$ & $\begin{array}{c}4,4 \pm 2,3 \\
62,8 \pm 34,4\end{array}$ & $>0.05$ \\
\hline & So sánh T1-T0** & $\mathrm{p} 1<0.05$ & $\mathrm{p} 2<0.05$ & \\
\hline & So sánh T5-T0** & p1 $<0.05$ & $\mathrm{p} 2<0.05$ & \\
\hline & So sánh T8-T0** & $\mathrm{p} 1<0.05$ & $\mathrm{p} 2<0.05$ & \\
\hline & So sánh T12-T0** & $\mathrm{p} 1<0.05$ & $\mathrm{p} 2<0.05$ & \\
\hline
\end{tabular}

**Pair sample- Test

Chú thích: p1: so sánh trước sau tại các thời điểm ở nhóm can thiệp. p2: so sánh trước sau tại các thời điểm ở nhóm chứng. p3: so sánh can thiệp với nhóm chứng tại các thời điểm nghiên cứu.

Nhân xét: Mức đô đau theo thang điểm VAS của nhóm được tiêm MD-Shoulder được cải thiên ngay tại từ thời điểm $\mathrm{T} 1(10,9 \%)$ và đạt tới $50 \%$ tại T5 và T8 kết quả có ý nghĩa thống kê $(\mathrm{p}<0,05)$; Tại thời điểm T12 mức cải thiện cao hơn so với nhóm chứng, song không có ý nghĩa thống kê $(p>0,05)$.

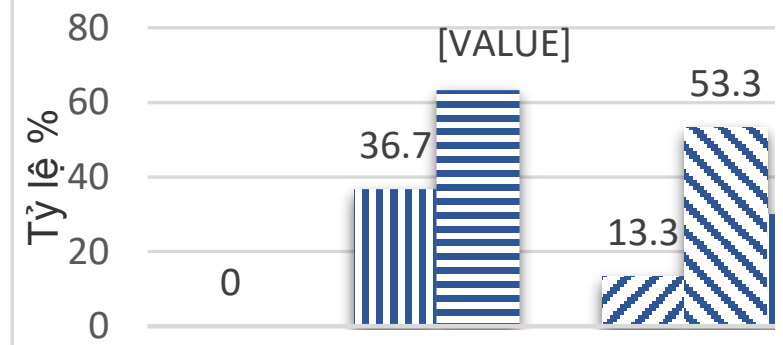

Biểu đồ 1: Phân bố Đ́TNC theo mức độ đau trên thang điểm VAS ở nhóm can thiệp $(n=30)$
Nhận xét: Có sự cải thiên mức độ đau sau 12 tuần so với trước điều trị của nhóm người bệnh tiêm MD-Shoulder $(p<0,05)$. Tai thời điểm trước nghiên cứu có $36,7 \%$ đau mức độ vừa và $63,3 \%$ đau mức độ nặng, sau 12 tuần điều trị có $66,7 \%$ BN đau mức đổ nhe và không đau và chỉ còn $3.3 \%$ BN đau mức độ vừa và nă̆ng $(83 \%$ bệnh nhân có cải thiện $30 \%$ thang điểm VAS sau 12 tuần điều trị).

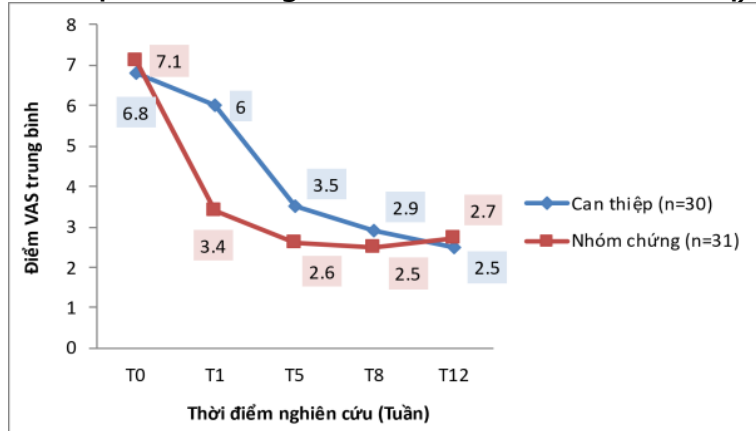

Biểu đồ 2: Đánh giá mức độ cải thiện thang điểm VAS 
Nhận xét: Điểm đau VAS trung bình ở nhóm can thiệp trong tuần đầu không có xu hướng giảm, trong khi ở nhóm chứng điểm đau VAS giảm nhanh chóng so với thời điểm trước khi điều trị. Sự khác biệt trên là có ý nghĩa thống kê với $p<0,05$.Sau 5 tuần điều trị, điểm đau VAS ở nhóm can thiệp giảm nhanh chóng vàsau 12 tuần điều trị, mức độ cải thiện điểm đau VAS là tương đương giữa hai nhóm.

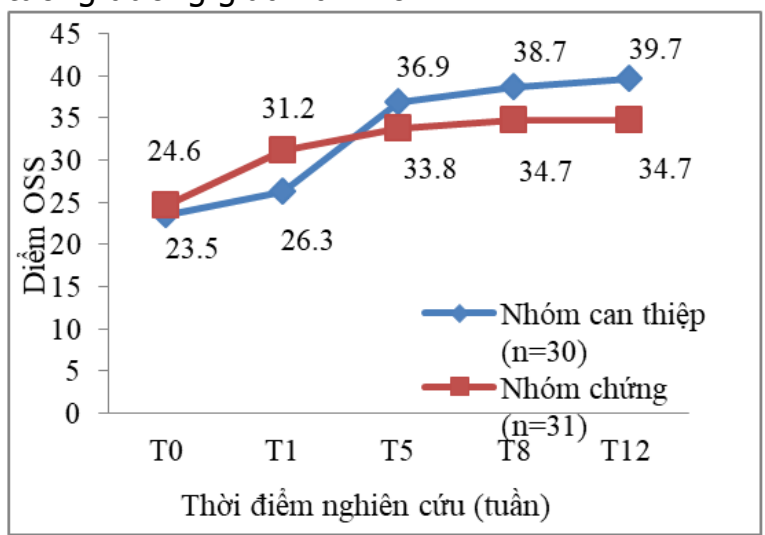

Biểu đồ 3: Đánh giá kêt quả điều trị theo thang điểm OSS và tỷ lệ cải thiện so với thời điếm TO

Nhận xét: Điểm OSS trung bình ở đối tượng nghiên cứu ở nhóm can thiệp cải thiện chậm hơn so với nhóm chứng ở thời điểm sau 1 tuần điều trị. Tuy nhiên, tại thời điểm5 tuần, 8 tuần, 12 tuần đều có điểm trung bình OSS ở nhóm can thiêp cao hơn so với nhóm chứng, sự khác biêt có ý nghĩa thống kê với $p<0,05$. Điểm OSS của nhóm can thiệp tăng lần lượt từ 23.5 tại thời điểm T0 tới 26.3 thời điểm T1, 36.9 tại T5, 38.7 tại $\mathrm{T} 8$ và 39.7 tại T12.

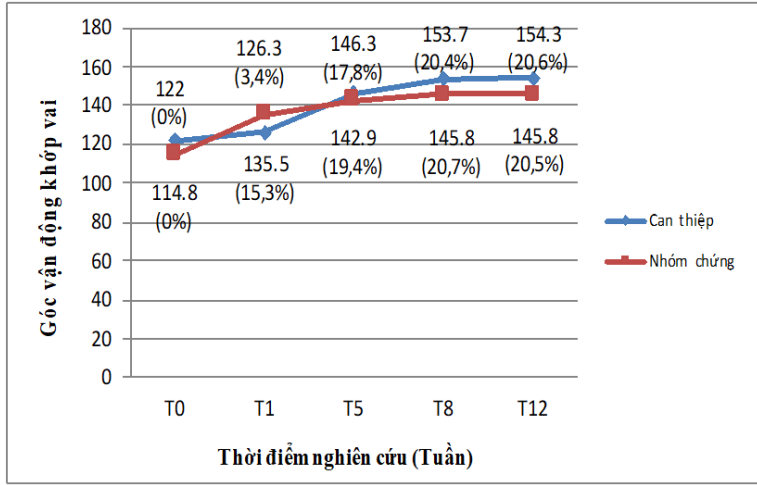

Biểu đồ 4. Kêt quả điều trị theo góc vận động (dạng) khớp vai và tỷ lệ cải thiện so với thời điểm TO $(n=30)$

Nhận xét: Cả 2 nhóm đều có sự cải thiện góc vận động khớp vai tứ thời điểm T1 đến T12 so với thời điểm bắt đầu nghiên cứu T0 với $\mathrm{p}<$ 0.05. Góc vận động trung bình của đối tượng nghiên cứu ở nhóm can thiệp cải thiện chậm hơn so với nhóm chứng ở thời điểm sau 1 tuần điều trị. Tuy nhiên, tỷ lệ cải thiện góc vận động từ tuần thứ 5 trở đi ở nhóm can thiệp tốt hơn so với nhóm chứngnhưng chưa thấy sự khác biệt rõ rệt giữa hai nhóm $p>0.05$.Góc vận động khớp vai của nhóm can thiệp tăng từ $114.8^{\circ}$ tại thời điểm T0 lên $146.3^{\circ}$ tại T5; $153.7^{\circ}$ tại T8; $154.3^{\circ}$ tại T12.

Bảng 3. Tác dưng không mong muốn sau tiêm thuốc (n=61)

\begin{tabular}{|c|c|c|c|c|c|}
\hline \multirow{2}{*}{ Triệu chứng } & \multicolumn{2}{|c|}{ Nhóm can thiệp(n=30) } & \multicolumn{2}{c|}{ Nhóm chứng(n=31) } & p \\
\cline { 2 - 6 } & $\mathbf{n}$ & $\mathbf{n}$ & $\mathbf{n}$ & $\mathbf{0}$ & \\
\hline \multicolumn{7}{|c|}{ Phản ứng sớm sau tiêm $\mathbf{3 0}$ phút } \\
\hline Đau đầu, chóng mặt & 0 & 0 & 2 & 6,5 & $<0,05$ \\
\hline Buồn nôn, nôn & 0 & 0 & 0 & 0 & \\
\hline Đauu tăng tại chồ & 4 & 13,3 & 3 & 9,7 & $>0,05$ \\
\hline
\end{tabular}

Nhận xét: Tỷ lệ xuất hiện triệu chứng đau đầu, chóng mặt ngay sau tiêm cao hơn ở nhóm chứng $(6,5)$, sự khác biệt có ý nghĩa thống kê với $p<0,05$. Tỷ lệ xuất hiện triệu chứng đau tăng sau tiêm ở nhóm can thiệp có $4 \mathrm{NB}(13,3 \%)$ và ở nhóm chứng có 3 bệnh nhẩn $(9,7 \%)$, sự khác biệt không có ý nghĩa thống kê. Sau 1 tuần theo dõi không thây các phản ứng phụ.

\section{BÀN LUÂ̂N}

MD-Shoulder cung cấp collagen dưới dạng tropocollagen, là đơn vị cơ bản nhất của các sợi collagen trong tổ chức gân cớ, sụn. Sau khi tiêm MD-Shoulder vào khu vực bị tổn thương, các sợi collagen tân tổng hợp lắng đọng vào khu vực bị tổn thương, tạo ra sự cải thiện đáng kể trong những đặc tính cơ học của mô bị tổn thương, thúc đẩy quá trình sửa chữa mô và hồi phục tổn thương gân ${ }^{6}$.

Kết quả nghiên cứu của chúng tôi (bảng 1) cho thấy độ tuổi trung bình của cả hai nhóm là $62,9 \pm 10,2$, tỷ lệ mắc bệnh ở nữ $(75,4 \%)$ cao hơn ở nam $(24,6 \%)$, chỉ số BMI trung bình là $23,1 \pm 2,5$, điểm VAS trung bình là $7,0 \pm 0,9$. Kết quả trong bảng 1 cũng thể hiện không có sự khác biệt về tuổi, giới, BMI, điểm đau VAS và chức năng vận động khớp vai giữa 2 nhóm tại 
thời điểm bắt đầu tham gia nghiên cứu.

Trong nghiên cứu của chúng tôi (biểu đồ 2): ở cả hai nhóm khi bắt đầu điều trị (TO) đều có điểm đau VAS trung bình ở mức đau vừa. Sau một tuần điều trị ( $\mathrm{T} 1)$, ở nhóm can thiệp không có xu hướng giảm, trong khi ở nhóm chứng điểm đau VAS giảm nhanh chóng so với thời điểm trước khi điều trị, sự khác biệt trên có ý nghĩa thống kê với $p<0,05$. Tuy nhiên, sau 5 tuần điều trị, điểm đau VAS ở nhóm can thiệp giảm rõ rệt, và tiếp tục giảm dần đến tuần 8 và tuần thứ 12, trong khi ở nhóm đối chứng điểm đau VAS giảm đến tuần 8 và bắt dầu có xu hướng tăng lên từ tuần thứ 12 . Mặc dù vậy, sự khác biệt về điểm đau trung bình giữa nhóm chứng và nhóm can thiệp tại các thời điểm sau 8 tuần và sau 12 tuần điều trị chưa có ý nghĩa thống kê. Ở biểu đồ 1 thể hiện sự phân bố tỷ lệ ĐTNC theo mức độ đau trên thang điểm VAS ở nhóm can thiệpsau điều trị cho thấy có sự cải thiện mức độ đau theo thang điểm VAS tại thời điểm tuần 12 so với trước điêu trị của nhóm người bệnh tiêm MD-Shoulder $(p<0,05)$. Tại thời điểm trước nghiên cứu có $36,7 \%$ đau mức độ vừa và $63,3 \%$ đau mức độ nặng, sau 12 tuần điêu trị có $66,7 \%$ $\mathrm{BN}$ đau mức độ nhẹ và không đau và chỉ còn $33.3 \%$ BN đau mức độ vừa và nặng. Một nghiên cứu tiền đề tại Ý dựa trên chùm ca bệnh tiêm Collagen tuýp 1 để điều trị viêm gân trên gai cũng cho kết quả là liệu pháp cho hiệu quả giảm đau tại thời điểm tuần thứ 2,1 tháng và 2 tháng sau khi bắt đầu điều trị ${ }^{9}$.

Chức năng vận động khớp vai được đánh giá bằng thang điểm OSS, kết quả nghiên cứu chỉ ra cả 2 phương pháp đều cải thiện chức năng của khớp vai bị đau và sự cải thiện này có ý nghĩa thống kê $(p<0,05)$. Tại thời điểm tuần thứ 5 , tuần thứ 8 và tuần thứ 12 sau điêuu trị, nhóm tiêm MD-Shoulder có sư cải thiên tốt hơn so với nhóm chứng, sự cải thiện có ý nghĩa thống kê với $p<0,05$ (biểu đồ 3 ). Theo nghiên cứu can thiệp tiêm MD - Shoulder trên 22 bệnh nhân viêm gân trên gai ở Bulgarie cũng mang lại sự cải thiện về vận động khớp vai tại thời điểm 1 tháng và 2 tháng sau khi kết thúc điều trị.

Đánh giá sự cải thiện biên độ hoạt động của khớp vai thông qua việc đo góc vận động trung bình của khớp ở các ĐTNC cũng chỉ ra là nhóm can thiệp cải thiện chậm hơn so với nhóm chứng ở thời điểm sau 1 tuần điều trị. Tuy nhiên, tỷ lệ cải thiện góc vận động từ tuần thứ 5 trở đi ở nhóm can thiêp tốt hơn so với nhóm chứng. Góc vân động khớp vai của nhóm can thiêp tăng từ 122,0 tại thời điểm T0 lên 148,3 tại T5; 153,7 tại
T8; 154,3 tại T12. Ở cả 2 nhóm nghiên cứu đều có sự cải thiện góc vận động khớp vai so với trước điều trị với $p<0,05$.

Như vậy nhóm bệnh nhân viêm gân trên gai được điêu trị bằng liệu pháp tiêm collagen $\mathrm{MD}$ Guna dưới hướng dẫn siêu âm đem lại kết quả tốt hơn trên thang điểm vận động khớp vai OSS. Thang điểm VAS, góc dạng cánh tay của nhóm can thiêp tai tuần thứ 12 sau điều trị cải thiên tốt hơn so với nhóm chứng. Mặc dù sự khác biệt chưa có ý nghĩa thống kê do thời gian nghiền cứu chưa đủ, và số lượng mẫu chưa đủ lớn nhưng cả 2 chỉ số này đều có xu hướng cải thiện tốt hơn trong khi đó ở nhóm chứng lại có xu hướng không tiếp tục cải thiện và bắt đầu có xu hướng xấu đi,điều này có thể giải thích do tác dụng ngắn hạn của Depo - Medrol nên mặc dù thuốc có tác dụng chống viêm mạnh nên các triệu chứng sẽ đỡ nhanh nhưng lại sớm có dấu hiệu tái phát.

Khảo sát các tác dụng không mong muốn trong 12 tuần điều trị của cả hai nhóm nghiên cứu cho thấy: tỷ lệ xuất hiện triệu chứng đau đầu, chóng mặt ngay sau tiêm cao hơn ở nhóm chứng $(6,5 \%)$, sự khác biệt có ý nghĩa thống kê với $p<0,05$. Sự khác biệt giữa tỷ lệ xuất hiện triệu chứng đau tăng sau tiêm ở nhóm can thiệp và ở nhóm chứngkhông có ý nghĩa thống kê.

\section{KẾT LUẬN}

Liệu pháp tiêm Collagen MD-Shoulder dưới hướng dấn siêu âm trong điều trị viêm gân trên gaicho hiệu quả cải thiện điểm đau VAS sau 1 tuần (tỷ lệ giảm so với To: 10,9\%), kéo dài đến 12 tuần sau điều trị (tỷ lệ giảm so với $\mathrm{TO}$ : $63,9 \%)$. Mức độ cải thiện điểm đau giữa nhóm tiêm Collagen MD-Shoulder là tương đương với nhóm tiêm Depo - Medrol sau 12 tuần điều trị. Cải thiện chức năng vận động khớp vai từ tuần thứ $1(11,0 \%)$ và kéo dài đến sau 12 tuần $(39,4 \%)$ ngoài ra mức độ cải thiện chức năng vận động tốt hơn so với tiêm Depo - Medrol từ tuần thứ 5 . Tỷ lệ đau tăng sau tiêm ở nhóm can thiệp là $13,3 \%$, không khác biệt có ý nghĩa thống kế so với nhóm chứng $(9,7 \%)$ với p>0,05

\section{TÀI LIÊU THAM KHẢO}

1. Trần Ngọc Ân. Viêm quanh khớp vai. Bệnh Thấp khớp. Nhà xuất bản Y Học 2002:364 - 374.

2. Rockwood CA, Matsen FA. The Shoulder. Saunders; 1990.

3. Lipman $K$, Wang $C$, Ting $K$, Soo $C$, Zheng $Z$. Tendinopathy: injury, repair, and current exploration. Drug design, development and therapy. 2018;12:591-603. doi:10.2147/ dddt.S154660 
4. Dean BJ, Lostis E, Oakley T, Rombach I, Morrey ME, Carr AJ. The risks and benefits of glucocorticoid treatment for tendinopathy: a systematic review of the effects of local glucocorticoid on tendon. Seminars in arthritis and rheumatism. Feb 2014;43(4):570-6. doi:10.1016/j. semarthrit.2013.08.006

5. Friedrichs J, Taubenberger A, Franz CM Muller DJ. Cellular remodelling of individual collagen fibrils visualized by time-lapse AFM. Journal of molecular biology. Sep 21 2007;372(3): 594-607. doi:10.1016/j.jmb.2007.06.078

6. Nestorova R, Rashkov R. Collagen injections Guna MDs in patients with acute periarthritis of the shoulder: clinical and sonographic assessment. 2013:S135-S136.
7. Nguyễn Quanh Quyên, Pham Văn Diêu. Atlas giải phẫu người, tài liệu dịch của tác giả Netter Frank H. NXB Y hoc 2007; 2007.

8. Rincón-Hurtado A $M$, Rocha-Buelvas $A$, López-Cardona A, Martínez JW. Health-related quality of life of patients with rotator cuff injuries, Cofee Triangle, Colombia, 2013. Revista brasileira de ortopedia. May-Jun 2018;53(3):364-372. doi:10.1016/j.rboe.2018.03.018

9. Corrado B, Bonini I, Chirico VA, et al. Ultrasound-guided collagen injections in the treatment of supraspinatus tendinopathy: a case series pilot study. Journal of biological regulators and homeostatic agents. May-Jun 2020;34(3 Suppl. 2):33-39. advances in musculoskeletal diseases and infections - sotimi 2019.

\section{KẾT QUẢ PHẪU THUÂT ĐIỀU TRỊ UNG THƯ BIỂU MÔ TUYẾN GIÁP THỂ BIÊTT HÓA TẠI BỆNH VIỆN K CƠ SỞ TÂN TRIỀU}

\section{TÓM TẮT}

Nghiên cứu tiến cứu được tiến hành trên 156 bệnh nhân ung thư tuyến giáp thể biệt hóa được phâuu thuât tại Bệnh viện $K$ cơ sở Tân Triều từ tháng 6/2020 đển tháng 6/2021 nhằm đánh giá kết quả phâu thuât ở nhóm bệnh nhân này. Tỷ lệ cắt toàn bộ tuyến giáp và vét hach cổ lần lướt là $75,6 \%$ và $90,4 \%$. Tỷ lệ di căn hach là $44,0 \%$, hay gặp nhất là nhóm hạch trung tâm $(61,3 \%)$. Thể mô bềnh hoc hay găp nhất là thể nhú (chiếm 92,9\%). Khàn tiếng và hạ canxi máu là hai biến chứng hay gặp nhất (chiếm lẩn lượt là $14,7 \%$ và $16 \%$ ), cao hơn ở nhóm cắt toàn bộ tuyển giáp.

Tư khóa: Ung thư tuyến giáp thể biệt hóa, kết quả phẫu thuật.

\section{SUMMARY \\ SURGICAL OUTCOME OF WELL- DIFFERENTIATED THYROID CANCER AT K HOSPITAL IN TAN TRIEU}

This is a prospective study on 156 cases with welldifferentiated thyroid carcinoma treated by surgery at K Hospital in Tan Trieu from June 2020 to June 2021 to evaluate surgical outcomes in this group of patients. The proportions of total thyroidectomy and lymph node dissection were $75.6 \%$ and $90.4 \%$ respectively. The rate of lymph node metastasis was $44.0 \%$, the most common are group center $(61.3 \%)$ The most common histopathological form is the papillary (92.9\%). Hoarse voice and hypocalcemia were the two most common complications, (accounting for $14.7 \%$ and $16.6 \%$ respectively), in

*Trường Đại học Y dược Thái Nguyên

**Bênh viền $K$

Chịu trách nhiệm chính: Nguyễn Tuấn Sơn

Email: tuanson9999@gmail.com

Ngày nhâan bài: 24.6.2021

Ngày phản biên khoa hoc: 18.8.2021

Ngày duyệt bài: 26.8.2021

\section{Nguyễn Tuấn Sơn*, Hàn Thị Vân Thanh**}

which patients with total thyroidectomy had higher rates.

Keywords: Differentiated thyroid cancer, surgical outcome.

\section{I. ĐĂT VẤN ĐỀ}

Ung thư tuyến giáp (UTTG) đứng đâu trong các ung thư hệ nội tiết, chiếm $90 \%$ và đang có xu hướng ngày một tăng. Theo GLOBOCAN 2018, trên thế giới UTTG đứng hàng thứ 11 trong số các loại ung thư nói chung với tổng số 567.233 ca mắc chiếm tỷ lệ 3,1\%, và 41.071 ca tử vong chiếm tỷ lệ 0,43\%. UTTG đứng hàng thứ 5 trong các loại ung thư ở nữ giới. Tỷ lê mắc chuẩn theo độ tuổi 6.7/100.000 dân, tỷ lệ nữ / nam là 3/1[6]. Tại Việt Nam, UTTG đứng hàng thứ 9 với 5.418 ca mới mắc, 528 ca tử vong mỗi năm, tỷ lê mắc chuẩn theo độ tuổi là 3,52/100.000 dân, đứng thứ 6 trong các loại ung thư ở nữ giới[6].

UTTG thể biệt hóa bao gồm thể nhú và thể nang, chiếm hơn 90\% các trường hợp[7]. Phẫu thuật là phương pháp điều trị chủ đạo trong ung thư tuyến giáp, các phương pháp khác có vai trò bổ trợ. Hiên nay có hai phương pháp phẫu thuât là cắt toàn bộ tuyến giáp và cắt thùy và eo tuyến có thể kèm theo vét hạch cổ tùy trường hợp.

Trong những năm gân đây, tỷ lệ UTTG thể biệt hóa gia tăng nhanh chóng trên toàn thế giới. Việc thực hiện rộng rãi tâm soát ung thư và sự sẵn có của siêu âm và các phương tiện chẩn đoán hỗ trợ khác đã giúp phát hiện được một lương lớn UUTTG ở giai đoan sớm, khối u nhỏ nguy cơ thấp[8]. Phân loai mới TNM của AJCC 2017, trong đó mức tuổi 55 được sử dụng làm mức "cut off" đã thay đổi chẩn đoán giai đoạn so 